\title{
WEAK AND STRONG CONVERGENCE THEOREMS FOR $m$-GENERALIZED HYBRID MAPPINGS IN HILBERT SPACES
}

\author{
Sattar Alizadeh - Fridoun Moradlou
}

\begin{abstract}
In this paper, we prove a weak convergence theorem of Ishikawa's type for $m$-generalized hybrid mappings in a Hilbert space. Further, by using a new modification of Ishikawa iteration, we prove a strong convergence theorem for $m$-generalized hybrid mappings in a Hilbert space.
\end{abstract}

\section{Introduction}

Throughout this paper, we denote by $\mathbb{N}$ and $\mathbb{R}$ the sets of positive integers and real numbers, respectively. Let $C$ be a nonempty, closed and convex subset of a real Hilbert space $H$. Then the self mapping $T$ of $C$ is called:

(i) nonexpansive, if $\|T x-T y\| \leq\|x-y\|$ for all $x, y \in C$;

(ii) firmly nonexpansive, if $\|T x-T y\|^{2} \leq\langle x-y, T x-T y\rangle$ for all $x, y \in C$;

(iii) nonspreading, if $2\|T x-T y\|^{2} \leq\|T x-y\|^{2}+\|T y-x\|^{2}$ for all $x, y \in C$;

(iv) hybrid, if $3\|T x-T y\|^{2} \leq\|x-y\|^{2}+\|T x-y\|^{2}+\|T y-x\|^{2}$ for all $x, y \in C$.

We denote by $F(T)$ the set of fixed points of $T$.

There exist some iteration processes which is often used to approximate a fixed point of a nonexpansive mapping: Picard iteration, Krasnosel'skiu iteration, Halpern iteration, Mann iteration and Ishikawa iteration. During the

2010 Mathematics Subject Classification. Primary 47H10, 47H09, 47J25, 47J05.

Key words and phrases. Fixed point, Hilbert space, hybrid method, strong convergence, weak convergence. 
recent years, Mann and Ishikawa iterative schemes [8], [15] have been studied by a number of authors.

In 1953, Mann [15] defined the following iteration procedure:

$$
\left\{\begin{array}{l}
x_{0} \in C \quad \text { chosen arbitrarily, } \\
x_{n+1}=\alpha_{n} x_{n}+\left(1-\alpha_{n}\right) T x_{n},
\end{array}\right.
$$

where $0 \leq \alpha_{n} \leq 1$ for all $n \in \mathbb{N} \cup\{0\}$.

In 1974, Ishikawa [8] defined the following iteration procedure:

$$
\left\{\begin{array}{l}
x_{0} \in C \quad \text { chosen arbitrarily, } \\
y_{n}=\beta_{n} x_{n}+\left(1-\beta_{n}\right) T x_{n}, \\
x_{n+1}=\alpha_{n} x_{n}+\left(1-\alpha_{n}\right) T y_{n},
\end{array}\right.
$$

where $0 \leq \alpha_{n} \leq \beta_{n} \leq 1$ for all $n \in \mathbb{N} \cup\{0\}$ and he proved strong convergence of the sequence $\left\{x_{n}\right\}$ generated by the above iterative scheme if $\lim _{n \rightarrow \infty} \beta_{n}=1$ and $\sum_{n=1}^{\infty}\left(1-\alpha_{n}\right)\left(1-\beta_{n}\right)=\infty$. By taking $\beta_{n}=1$ for all $n \geq 0$ in (1.2), Ishikawa iteration process reduces to Mann iteration process.

Process (1.2) is indeed more general than process (1.1). But research has been done on the latter due probably to reasons that the formulation of process (1.1) is simpler than that of (1.2) and that a convergence theorem for process (1.1) may lead to a convergence theorem for process (1.2) provided that $\left\{\beta_{n}\right\}$ satisfies certain appropriate conditions. On the other hand, the process (1.1) may fail to converge while process (1.2) can still converge for a Lipschitz pseudocontractive mapping in a Hilbert space [3]. Actually, Mann and Ishikawa iteration processes have only weak convergence, in general (see [4]).

Recently, to obtain strong convergence, many mathematicians have been extensively considered modified processes. Nakajo and Takahashi [19] proposed the following modification of the Mann's iteration for a nonexpansive self mapping $T$ of $C$ in a Hilbert space $H$ :

$$
\left\{\begin{array}{l}
x_{0} \in C \quad \text { chosen arbitrarily, } \\
y_{n}=\alpha_{n} x_{n}+\left(1-\alpha_{n}\right) T x_{n}, \\
C_{n}=\left\{z \in C:\left\|y_{n}-z\right\| \leq\left\|x_{n}-z\right\|\right\}, \\
Q_{n}=\left\{z \in C:\left\langle x_{n}-z, x_{0}-x_{n}\right\rangle \geq 0\right\} \\
x_{n+1}=P_{C_{n} \cap Q_{n}} x_{0}
\end{array}\right.
$$

where $P_{K}$ denotes the metric projection from $H$ onto a closed convex subset $K$ of $H$. They proved strong convergence of the sequence $\left\{x_{n}\right\}$, if the sequence $\left\{\alpha_{n}\right\}$ is bounded above from one.

In 2006, Martinez-Yanes and Xu [17] introduced the following modified Ishikawa iteration process for a nonexpansive self mapping $T$ of $C$ with $F(T) \neq \emptyset$ 
in a Hilbert space $H$ :

$$
\left\{\begin{aligned}
x_{0} \in C \quad \text { chosen arbitrarily, } & \\
z_{n}= & \beta_{n} x_{n}+\left(1-\beta_{n}\right) T x_{n}, \\
y_{n}= & \alpha_{n} x_{n}+\left(1-\alpha_{n}\right) T z_{n}, \\
C_{n}= & \left\{v \in C:\left\|y_{n}-v\right\|^{2} \leq\left\|x_{n}-v\right\|^{2}\right. \\
& \left.\quad+\left(1-\alpha_{n}\right)\left(\left\|z_{n}\right\|^{2}-\left\|x_{n}\right\|^{2}+2\left\langle x_{n}-z_{n}, v\right\rangle \geq 0\right)\right\} \\
Q_{n}= & \left\{v \in C:\left\langle x_{n}-v, x_{0}-x_{n}\right\rangle \geq 0\right\}, \\
x_{n+1}= & P_{C_{n} \cap Q_{n}} x_{0},
\end{aligned}\right.
$$

where $\left\{\alpha_{n}\right\}$ and $\left\{\beta_{n}\right\}$ are sequences in $[0,1]$. They proved that if $\left\{\alpha_{n}\right\}$ bounded above from one and $\lim _{n \rightarrow \infty} \beta_{n}=1$, then the sequence $\left\{x_{n}\right\}$ converges strongly to $P_{F(T)} x_{0}$.

Very recently, Hojo et al. [6] proved some strong convergence theorems by hybrid methods for 2-generalized hybrid mappings in a Hilbert space.

In this paper, employing the idea of Nakajo and Takahashi [19], we modify Ishikawa iteration process for $m$-generalized hybrid mappings in a Hilbert space. This paper is organized as follows: In Section 2, we give some preliminaries which will used in next sections. In Section 3, by using Banach limits, we prove a fixed point theorem for $m$-generalized hybrid mappings in a Hilbert space. In Section 4, we prove some weak and strong convergence theorems for $m$-generalized hybrid mappings in a Hilbert space.

\section{Preliminaries}

Assume that $H$ be a (real) Hilbert space with inner product $\langle\cdot, \cdot\rangle$ and norm $\|\cdot\|$. We denote the weak convergence and the strong convergence of $\left\{x_{n}\right\}$ to $x \in H$ by $x_{n} \rightarrow x$ and $x_{n} \rightarrow x$, respectively.

Now we recall some basic properties of Hilbert spaces which we will use in next section. For $x, y \in H$, we have

$$
\|\alpha x+(1-\alpha) y\|^{2}=\alpha\|x\|^{2}+(1-\alpha)\|y\|^{2}-\alpha(1-\alpha)\|x-y\|^{2},
$$

for all $\alpha \in \mathbb{R}$,

$$
\|x+y\|^{2} \leq\|x\|^{2}+2\langle y, x+y\rangle
$$

and

$$
\|x-y\|^{2}=\|x\|^{2}-\|y\|^{2}-2\langle x-y, y\rangle .
$$

It is well known that a Hilbert space $H$ satisfies the Opial condition, i.e. if $\left\{x_{n}\right\}$ is a sequence in $H$ such that $x_{n} \rightarrow x$ and $x \neq y$, then

$$
\liminf _{n \rightarrow \infty}\left\|x_{n}-x\right\|<\liminf _{n \rightarrow \infty}\left\|x_{n}-y\right\| .
$$


A self mapping $T$ of $C$ with $F(T) \neq \emptyset$ is called quasi-nonexpansive if $\|x-T y\| \leq$ $\|x-y\|$ for all $x \in F(T)$ and $y \in C$. It is well-known that for a quasi-nonexpansive mapping $T, F(T)$ is closed and convex [9]. Let $K$ be a closed and convex subset of $H$ and let $P_{K}$ be metric (or nearest point) projection from $H$ onto $K$ (i.e. for $x \in H, P_{K} x$ is the only point in $K$ such that $\left.\left\|x-P_{K} x\right\|=\inf \{\|x-z\|: z \in K\}\right)$. Let $x \in H$ and $z \in K$, then $z=P_{K} x$ if and only if there holds the relation:

$$
\langle x-z, y-z\rangle \leq 0
$$

for all $y \in K$. For more details we refer readers to [1], [21].

Using Opial condition, we can deduce the following lemma:

Lemma 2.1 ([27]). Let $H$ be a Hilbert space and $\left\{x_{n}\right\}$ be a sequence in $H$ such that there exists a nonempty subset $E \subset H$ satisfying

(a) For every $x^{*} \in E, \lim _{n \rightarrow \infty}\left\|x_{n}-x^{*}\right\|$ exists.

(b) If a subsequence $\left\{x_{n_{j}}\right\} \subset\left\{x_{n}\right\}$ converges weakly to $x^{*}$, then $x^{*} \in E$, then there exists $x_{0} \in E$ such that $x_{n} \rightarrow x_{0}$.

We will use the following lemmas in the proof of our main results in next section.

Lemma 2.2 ([23]). Let $H$ be a Hilbert space and $E$ be a nonempty, closed and convex subset of $H$. Let $\left\{x_{n}\right\}$ be a sequence in $H$. If $\left\|x_{n+1}-x\right\| \leq\left\|x_{n}-x\right\|$ for all $n \in \mathbb{N}$ and $x \in E$, then $\left\{P_{E}\left(x_{n}\right)\right\}$ converges strongly to some $z \in E$, where $P_{E}$ stands for the metric projection on $H$ onto $E$.

Lemma 2.3 ([17]). Let $H$ be a real Hilbert space. Given a closed and convex subset $C \subset H$ and points $x, y, z \in H$. Given also a real number $a \in \mathbb{R}$. The set

$$
D:=\left\{u \in C:\|y-u\|^{2} \leq\|x-u\|^{2}+\langle z, u\rangle+a\right\}
$$

is convex (and closed).

Let $C$ be a nonempty, closed and convex subset of $H$. A self mapping $T$ of $C$ is called generalized hybrid [12] if there exist $\alpha, \beta \in \mathbb{R}$ such that

$$
\alpha\|T x-T y\|^{2}+(1-\alpha)\|x-T y\|^{2} \leq \beta\|T x-y\|^{2}+(1-\beta)\|x-y\|^{2}
$$

for all $x, y \in C$. We call such a mapping an $(\alpha, \beta)$-generalized hybrid mapping. It easy to see that

- (1,0)-generalized hybrid mapping is nonexpansive;

- $(2,1)$-generalized hybrid mapping is nonspreading;

- $(3 / 2,1 / 2)$-generalized hybrid mapping is hybrid.

Let $m \in \mathbb{N}$, a self mapping $T$ of $C$ is called $m$-generalized hybrid [18] if there exist $\alpha_{1}, \ldots, \alpha_{m}, \beta_{1}, \ldots, \beta_{m} \in \mathbb{R}$ such that 


$$
\begin{aligned}
\sum_{k=1}^{m} \alpha_{k}\left\|T^{m+1-k} x-T y\right\|^{2} & +\left(1-\sum_{k=1}^{m} \alpha_{k}\right)\|x-T y\|^{2} \\
& \leq \sum_{k=1}^{m} \beta_{k}\left\|T^{m+1-k} x-y\right\|^{2}+\left(1-\sum_{k=1}^{m} \beta_{k}\right)\|x-y\|^{2}
\end{aligned}
$$

for all $x, y \in C$. Therefore, $T$ is 2-generalized hybrid mapping if $\alpha_{1}, \alpha_{2}, \beta_{1}, \beta_{2} \in \mathbb{R}$ such that

$$
\begin{aligned}
\alpha_{1}\left\|T^{2} x-T y\right\|^{2} & +\alpha_{2}\|T x-T y\|^{2}+\left(1-\alpha_{1}-\alpha_{2}\right)\|x-T y\|^{2} \\
& \leq \beta_{1}\left\|T^{2} x-y\right\|^{2}+\beta_{2}\|T x-y\|^{2}+\left(1-\beta_{1}-\beta_{2}\right)\|x-y\|^{2}
\end{aligned}
$$

for all $x, y \in C$. In [6], Hojo et al. give two examples of 2-generalized hybrid mapping which are not generalized hybrid mappings. Therefore, class of 2generalized hybrid mappings is broader than generalized hybrid mappings.

Also, one can easily show that $m$-generalized hybrid mapping is quasi-nonexpansive if the set of it's fixed points is nonempty.

\section{Fixed point theorem by using Banach limit}

In this section, we recall the notion of Banach limits and some properties of them. For more details, we refer to readers to [1], [21].

Denote by $l^{\infty}$ the set of all bounded sequences equipped with supremum norm.

Definition 3.1. A continuous linear functional $\mu$ on $l^{\infty}$ is called a Banach limit if

(a) $\mu(e)=\|e\|=1$, where $e=(1,1,1, \ldots)$,

(b) $\mu_{n}\left(x_{n}\right)=\mu_{n}\left(x_{n+1}\right)$ for all $x=\left(x_{1}, x_{2}, \ldots\right) \in l^{\infty}$, where $\mu_{n}\left(x_{n+m}\right)=$ $\mu\left(x_{m+1}, \ldots, x_{m+n}, \ldots\right)$.

As usual, we denote by $\mu_{n}\left(x_{n}\right)$ the value of $\mu$ at $x=\left(x_{1}, x_{2}, \ldots\right)$. It is well known that there exists a Banach limit on $l^{\infty}$. Let $\mu$ be a Banach limit. Then

$$
\liminf _{n \rightarrow \infty} x_{n} \leq \mu_{n}\left(x_{n}\right) \leq \limsup _{n \rightarrow \infty} x_{n} .
$$

Moreover, if $x_{n} \rightarrow a$, then $\mu_{n}\left(x_{n}\right)=a$. Takahashi and Yao [24], by using Banach limits, proved the following theorem:

TheOREM 3.2. Let $H$ be a Hilbert space and $C$ be a nonempty, closed and convex subset of $H$ and let $T$ be a self mapping of $C$. Assume that there exists an element $x \in C$ such that $\left\{T^{n} x\right\}$ is bounded and

$$
\mu_{n}\left\|T^{n} x-T y\right\|^{2} \leq \mu_{n}\left\|T^{n} x-y\right\|^{2},
$$

for all $y \in C$ and for some Banach limit $\mu$. Thus, $T$ has a fixed point in $C$.

Now, we prove main result of this section. 
TheOREM 3.3. Let $C$ be a nonempty, closed and convex subset of a Hilbert space $H$ and $T$ be $m$-generalized hybrid self mapping of $C$. If $\left\{T^{n} z\right\}$ is bounded for some $z \in C$, then $T$ has a fixed point in $C$ and vice versa.

Proof. Since $T$ is a $m$-generalized hybrid self mapping of $C$, then

$$
\begin{aligned}
\sum_{k=1}^{m} \alpha_{k}\left\|T^{m+1-k} x-T y\right\|^{2} & +\left(1-\sum_{k=1}^{m} \alpha_{k}\right)\|x-T y\|^{2} \\
& \leq \sum_{k=1}^{m} \beta_{k}\left\|T^{m+1-k} x-y\right\|^{2}+\left(1-\sum_{k=1}^{m} \beta_{k}\right)\|x-y\|^{2},
\end{aligned}
$$

for all $x, y \in C$. Let $z \in C$ such that $\left\{T^{n} z\right\}$ is bounded. Assume that $\mu$ is a Banach limit. Thus, for all $y \in C$ and $n \in \mathbb{N} \cup\{0\}$, we get

$$
\begin{aligned}
\sum_{k=1}^{m} \alpha_{k}\left\|T^{n+m+1-k} z-T y\right\|^{2}+\left(1-\sum_{k=1}^{m} \alpha_{k}\right)\left\|T^{n} z-T y\right\|^{2} \\
\leq \sum_{k=1}^{m} \beta_{k}\left\|T^{n+m+1-k} z-y\right\|^{2}+\left(1-\sum_{k=1}^{m} \beta_{k}\right)\left\|T^{n} z-y\right\|^{2},
\end{aligned}
$$

for all $y \in C$. By using boundedness of $\left\{T^{n} z\right\}$, we can take a Banach limit $\mu$ to both sides of the inequality (3.1). So, we get

$$
\begin{aligned}
& \sum_{k=1}^{m} \alpha_{k} \mu_{n}\left\|T^{n+m+1-k} z-T y\right\|^{2}+\left(1-\sum_{k=1}^{m} \alpha_{k}\right) \mu_{n}\left\|T^{n} z-T y\right\|^{2} \\
& \leq \sum_{k=1}^{m} \beta_{k} \mu_{n}\left\|T^{n+m+1-k} z-y\right\|^{2}+\left(1-\sum_{k=1}^{m} \beta_{k}\right) \mu_{n}\left\|T^{n} z-y\right\|^{2},
\end{aligned}
$$

and therefore

$$
\begin{aligned}
\left(\sum_{k=1}^{m} \alpha_{k}\right) \mu_{n} \| T^{n} z & -T y\left\|^{2}+\left(1-\sum_{k=1}^{m} \alpha_{k}\right) \mu_{n}\right\| T^{n} z-T y \|^{2} \\
& \leq\left(\sum_{k=1}^{m} \beta_{k}\right) \mu_{n}\left\|T^{n} z-y\right\|^{2}+\left(1-\sum_{k=1}^{m} \beta_{k}\right) \mu_{n}\left\|T^{n} z-y\right\|^{2} .
\end{aligned}
$$

This yields

$$
\mu_{n}\left\|T^{n} z-T y\right\|^{2} \leq \mu_{n}\left\|T^{n} z-y\right\|^{2},
$$

for all $y \in C$. By Theorem 3.2, we have a fixed point in $C$.

Conversely, let $F(T)$ be nonempty, then there exists a $z \in F(T)$ and therefore $\left\{T^{n} z\right\}=\{z\}$. Thus $\left\{T^{n} z\right\}$ is bounded.

Since the class of $m$-generalized hybrid mappings contain the class of nonexpansive mappings, nonspreading mappings, hybrid mappings and generalized hybrid mappings, we have the following corollaries. 
Corollary 3.4. Let $C$ be a nonempty, closed and convex subset of a Hilbert space $H$ and let $T$ be a generalized hybrid self mapping of $C$. Then $T$ has a fixed point in $C$ if and only if $\left\{T^{n} x\right\}$ is bounded for some $x \in C$.

Corollary 3.5. Let $H$ be a Hilbert space and let $C$ be a nonempty closed convex subset of $H$. Let $T$ be a nonexpansive self mapping of $C$. Then $T$ has a fixed point in $C$ if and only if $\left\{T^{n} x\right\}$ is bounded for some $x \in C$.

Corollary 3.6 ([13]). Let $H$ be a Hilbert space and let $C$ be a nonempty, closed and convex subset of $H$. Let $T$ be a nonspreading self mapping of $C$. Then $T$ has a fixed point in $C$ if and only if $\left\{T^{n} x\right\}$ is bounded for some $x \in C$.

Corollary 3.7 ([22]). Let $H$ be a Hilbert space and $C$ be a nonempty, closed and convex subset of $H$. Let $T$ be a hybrid self mapping of $C$. Then $T$ has a fixed point in $C$ if and only if $\left\{T^{n} x\right\}$ is bounded for some $x \in C$.

\section{Weak and strong convergence theorems of Ishikawa's type}

In this section, we prove some weak and strong convergence theorems of Ishikawa's type related to $m$-generalized hybrid mappings.

THEOREM 4.1. Let $C$ be a nonempty, closed and convex subset of a real Hilbert space $H$ and $T$ be a m-generalized hybrid self mapping of $C$ with $F(T) \neq \phi$ and $\left\|T^{2} x-T x\right\| \leq\|T x-x\|$ for all $x \in C$. Assume that $\left\{x_{n}\right\}$ is a sequence generated by

$$
\left\{\begin{array}{l}
x_{1}=x \in C \\
y_{n}=\left(1-\lambda_{n}\right) x_{n}+\lambda_{n} T x_{n} \\
x_{n+1}=\left(1-\gamma_{n}\right) x_{n}+\gamma_{n} T y_{n}
\end{array}\right.
$$

where $0 \leq \gamma_{n}, \lambda_{n} \leq 1$ for all $n \in \mathbb{N}$, $\liminf _{n \rightarrow \infty} \lambda_{n}\left(1-\lambda_{n}\right)>0$ and $0<a<\gamma_{n}<$ $b<1$. Then $x_{n} \rightarrow x_{0} \in F(T)$, where $x_{0}=\lim _{n \rightarrow \infty} P_{F(T)}\left(x_{n}\right)$.

Proof. By hypothesis, $T$ is a $m$-generalized hybrid mapping such that $F(T) \neq \phi$, so $T$ is quasi-nonexpansive. Then, for all $q \in F(T)$ and all $n \in \mathbb{N}$, we have

$$
\begin{aligned}
\left\|y_{n}-q\right\|^{2}= & \left(1-\lambda_{n}\right)\left\|x_{n}-q\right\|^{2} \\
& +\lambda_{n}\left\|T x_{n}-q\right\|^{2}-\lambda_{n}\left(1-\lambda_{n}\right)\left\|x_{n}-T x_{n}\right\|^{2} \\
\leq & \left(1-\lambda_{n}\right)\left\|x_{n}-q\right\|^{2}+\lambda_{n}\left\|x_{n}-q\right\|^{2}-\lambda_{n}\left(1-\lambda_{n}\right)\left\|x_{n}-T x_{n}\right\|^{2} \\
= & \left\|x_{n}-q\right\|^{2}-\lambda_{n}\left(1-\lambda_{n}\right)\left\|x_{n}-T x_{n}\right\|^{2}
\end{aligned}
$$

and hence

$$
\begin{aligned}
& \left\|x_{n+1}-q\right\|^{2}=\left\|\left(1-\gamma_{n}\right) x_{n}+\gamma_{n} T y_{n}-q\right\|^{2} \\
& \quad=\left(1-\gamma_{n}\right)\left\|x_{n}-q\right\|^{2}+\gamma_{n}\left\|T y_{n}-q\right\|^{2}-\gamma_{n}\left(1-\gamma_{n}\right)\left\|x_{n}-T y_{n}\right\|^{2}
\end{aligned}
$$




$$
\begin{aligned}
& \leq\left(1-\gamma_{n}\right)\left\|x_{n}-q\right\|^{2}+\gamma_{n}\left\|y_{n}-q\right\|^{2}-\gamma_{n}\left(1-\gamma_{n}\right)\left\|x_{n}-T y_{n}\right\|^{2} \\
\leq & \left(1-\gamma_{n}\right)\left\|x_{n}-q\right\|^{2}+\gamma_{n}\left\|x_{n}-q\right\|^{2} \\
& \quad-\gamma_{n} \lambda_{n}\left(1-\lambda_{n}\right)\left\|x_{n}-T x_{n}\right\|^{2}-\gamma_{n}\left(1-\gamma_{n}\right)\left\|x_{n}-T y_{n}\right\|^{2} \\
\leq & \left\|x_{n}-q\right\|^{2}-\gamma_{n} \lambda_{n}\left(1-\lambda_{n}\right)\left\|x_{n}-T x_{n}\right\|^{2} \leq\left\|x_{n}-q\right\|^{2} .
\end{aligned}
$$

So, we can conclude that $\lim _{n \rightarrow \infty}\left\|x_{n}-q\right\|$ exists. This yields that $\left\{x_{n}\right\},\left\{y_{n}\right\}$ and $\left\{T y_{n}\right\}$ are bounded. It follows from (4.2) that

$$
\left\|x_{n+1}-q\right\|^{2} \leq\left\|x_{n}-q\right\|^{2}-\gamma_{n} \lambda_{n}\left(1-\lambda_{n}\right)\left\|x_{n}-T x_{n}\right\|^{2} .
$$

By using $0<a<\gamma_{n}<b<1$, it is easy to see that

$$
\left\|x_{n+1}-q\right\|^{2} \leq\left\|x_{n}-q\right\|^{2}-a \lambda_{n}\left(1-\lambda_{n}\right)\left\|x_{n}-T x_{n}\right\|^{2} .
$$

Also, we have

$$
0 \leq a \lambda_{n}\left(1-\lambda_{n}\right)\left\|x_{n}-T x_{n}\right\|^{2} \leq\left\|x_{n}-q\right\|^{2}-\left\|x_{n+1}-q\right\|^{2} \rightarrow 0
$$

as $n \rightarrow \infty$, since $\liminf _{n \rightarrow \infty} \lambda_{n}\left(1-\lambda_{n}\right)>0$. Therefore

$$
\lim _{n \rightarrow \infty}\left\|x_{n}-T x_{n}\right\|=0 .
$$

Now, boundedness of $\left\{x_{n}\right\}$ implies that there exists a subsequence $\left\{x_{n_{i}}\right\}$ of $\left\{x_{n}\right\}$ such that $x_{n_{i}} \rightarrow x^{*} \in C$. Since $T$ is a $m$-generalized hybrid mapping, then

$$
\begin{aligned}
\sum_{k=1}^{m} \alpha_{k}\left\|T^{m+1-k} x-T y\right\|^{2} & +\left(1-\sum_{k=1}^{m} \alpha_{k}\right)\|x-T y\|^{2} \\
& \leq \sum_{k=1}^{m} \beta_{k}\left\|T^{m+1-k} x-y\right\|^{2}+\left(1-\sum_{k=1}^{m} \beta_{k}\right)\|x-y\|^{2},
\end{aligned}
$$

hence

$$
\begin{array}{rl}
0 \leq \sum_{k=1}^{m} \beta_{k} \| T^{m+1-k} & x-y\left\|^{2}+\left(1-\sum_{k=1}^{m} \beta_{k}\right)\right\| x-y \| \\
& -\sum_{k=1}^{m} \alpha_{k}\left\|T^{m+1-k} x-T y\right\|^{2}-\left(1-\sum_{k=1}^{m} \alpha_{k}\right)\|x-T y\|,
\end{array}
$$

replacing $x$ and $y$ by $x_{n}$ and $x^{*}$ in above inequality, respectively, we get

$$
\begin{aligned}
0 \leq & \sum_{k=1}^{m} \beta_{k}\left(\left\|T^{m+1-k} x_{n}\right\|^{2}-2\left\langle T^{m+1-k} x_{n}, x^{*}\right\rangle+\left\|x^{*}\right\|^{2}\right) \\
& +\left(1-\sum_{k=1}^{m} \beta_{k}\right)\left(\left\|x_{n}\right\|^{2}-2\left\langle x_{n}, x^{*}\right\rangle+\left\|x^{*}\right\|^{2}\right) \\
& -\sum_{k=1}^{m} \alpha_{k}\left(\left\|T^{m+1-k} x_{n}\right\|^{2}-2\left\langle T^{m+1-k} x_{n}, T x^{*}\right\rangle+\left\|T x^{*}\right\|^{2}\right)
\end{aligned}
$$




$$
\begin{aligned}
& -\left(1-\sum_{k=1}^{m} \alpha_{k}\right)\left(\left\|T^{n+1-k} x_{n}\right\|^{2}-2\left\langle x_{n}, T x^{*}\right\rangle+\left\|T x^{*}\right\|^{2}\right) \\
= & \left\|x^{*}\right\|^{2}-\left\|T x^{*}\right\|^{2}+\sum_{k=1}^{m}\left(\beta_{k}-\alpha_{k}\right)\left(\left\|T^{m+1-k} x_{n}\right\|^{2}-\left\|x_{n}\right\|^{2}\right) \\
& +2 \sum_{k=1}^{m} \alpha_{k}\left\langle T^{m+1-k}-x_{n}, T x^{*}\right\rangle \\
& -2 \sum_{k=1}^{m} \beta_{k}\left\langle T^{m+1-k} x_{n}-x_{n}, x^{*}\right\rangle+2\left\langle x_{n}, T x^{*}-x^{*}\right\rangle \\
\leq & \left\|x^{*}\right\|^{2}-\left\|T x^{*}\right\|^{2}+\sum_{k=1}^{m}\left(\beta_{k}-\alpha_{k}\right)\left(\left\|T^{m+1-k} x_{n}\right\|\right. \\
& \left.+\left\|x_{n}\right\|\right)\left(\left\|T^{m+1-k} x_{n}-x_{n}\right\|\right)+2 \sum_{k=1}^{m} \alpha_{k}\left\langle T^{m+1-k} x_{n}-x_{n}, T x^{*}\right\rangle \\
& -2 \sum_{k=1}^{m} \beta_{k}\left\langle T^{m+1-k} x_{n}-x_{n}, x^{*}\right\rangle+2\left\langle x_{n}, T x^{*}-x^{*}\right\rangle .
\end{aligned}
$$

Now, substituting $n$ by $n_{i}$, we have

$$
\begin{aligned}
0 \leq & \left\|x^{*}\right\|^{2}-\left\|T x^{*}\right\|^{2}+\sum_{k=1}^{m}\left(\beta_{k}-\alpha_{k}\right)\left(\left\|T^{m+1-k} x_{n_{i}}\right\|\right. \\
& \left.+\left\|x_{n_{i}}\right\|\right)\left(\left\|T^{m+1-k} x_{n_{i}}-x_{n_{i}}\right\|\right)+2 \sum_{k=1}^{m} \alpha_{k}\left\langle T^{m+1-k} x_{n_{i}}-x_{n_{i}}, T x^{*}\right\rangle \\
& -2 \sum_{k=1}^{m} \beta_{k}\left\langle T^{m+1-k} x_{n_{i}}-x_{n_{i}}, x^{*}\right\rangle+2\left\langle x_{n_{i}}, T x^{*}-x^{*}\right\rangle
\end{aligned}
$$

for all $i \in \mathbb{N}$. Since $x_{n_{i}} \rightarrow x^{*}$ as $i \rightarrow \infty$, it follows from (4.3) and (4.4) that

$$
\begin{aligned}
0 & \leq\left\|x^{*}\right\|^{2}-\left\|T x^{*}\right\|^{2}+2\left\langle x^{*}, T x^{*}-x^{*}\right\rangle \\
& =2\left\langle x^{*}, T x^{*}\right\rangle-\left\|x^{*}\right\|^{2}-\left\|T x^{*}\right\|^{2}=-\left\|x^{*}-T x^{*}\right\|^{2} .
\end{aligned}
$$

So, we have $T x^{*}=x^{*}$, i.e. $x^{*} \in F(T)$. Therefore the condition (b) of Lemma 2.1 satisfies for $E=F(T)$. On the other hand, we see that $\lim _{n \rightarrow \infty}\left\|x_{n}-q\right\|$ exists for $q \in F(T)$. Hence, it follows from Lemma 2.1 that there exists $x_{0} \in F(T)$ such that $\left\{x_{n}\right\}$ is weakly convergent to $x_{0}$ as $n \rightarrow \infty$. In addition, for all $q \in F(T)$, we have $\left\|x_{n+1}-q\right\| \leq\left\|x_{n}-q\right\|$, for all $n \in \mathbb{N}$. So, Lemma 2.2 implies that there exists some $x \in F(T)$ such that $P_{F(T)}\left(x_{n}\right) \rightarrow x$. Then

$$
\left\langle x_{0}-P_{F(T)}\left(x_{n}\right), x_{n}-P_{F(T)}\left(x_{n}\right)\right\rangle \leq 0 .
$$

Hence, we get $\left\langle x_{0}-x, x_{0}-x\right\rangle=\left\|x_{0}-x\right\|^{2} \leq 0$. Therefore $x_{0}=x$, i.e. $x_{n} \rightarrow$ $x_{0}=\lim _{n \rightarrow \infty} P_{F(T)}\left(x_{n}\right)$. 
TheOREM 4.2. Let $C$ be a nonempty, closed and convex subset of a real space $H$ and $T$ be a m-generalized hybrid self mapping of $C$ with $F(T) \neq \phi$. Assume that $\left\{\gamma_{n}\right\}$ and $\left\{\lambda_{n}\right\}$ are sequences in $[0,1]$ such that $0 \leq \gamma_{n} \leq \delta<1$ and $\lambda_{n} \rightarrow 1$ as $n \rightarrow \infty$. If $\left\{x_{n}\right\}$ in $C$ is a sequence generated by

$$
\left\{\begin{aligned}
x_{1}= & x \in C, \\
y_{n}= & \gamma_{n} x_{n}+\frac{1-\gamma_{n}}{n} \sum_{k=0}^{n-1} T^{k} z_{n}, \\
z_{n}= & \lambda_{n} x_{n}+\left(1-\lambda_{n}\right) T x_{n}, \\
C_{n}= & \{u \in C: \\
& \left.\left\|y_{n}-u\right\|^{2} \leq\left\|x_{n}-u\right\|^{2}+\left(1-\gamma_{n}\right)\left(\left\|z_{n}\right\|^{2}-\left\|x_{n}\right\|^{2}+2\left\langle x_{n}-z_{n}, u\right\rangle\right)\right\}, \\
Q_{n}= & \left\{u \in C:\left\langle x_{n}-u, x_{n}-x\right\rangle \leq 0\right\}, \\
x_{n+1}= & P_{C_{n} \cap Q_{n}} x,
\end{aligned}\right.
$$

then $\left\{x_{n}\right\}$ converges strongly to $P_{F(T)} x$.

Proof. Since $T$ is a $m$-generalized hybrid mapping such that $F(T) \neq \phi, T$ is quasi-nonexpansive. So $F(T)$ is closed and convex. Therefore we can define the metric projection from $H$ onto $F(T)$. It is easily seen that $C_{n}$ is closed and $Q_{n}$ is closed and convex for all $n \in \mathbb{N}$. Also, by Lemma 2.3, $C_{n}$ is convex. So $C_{n} \cap Q_{n}$ is closded and convex for all $n \in \mathbb{N}$. Let $u \in F(T)$ and put $w_{n}=(1 / n) \sum_{k=0}^{n-1} T^{k} z_{n}$ for all $n \in \mathbb{N}$. Since $T$ is quasi-nonexpansive, we have

$$
\begin{aligned}
\left\|w_{n}-u\right\| & =\left\|\frac{1}{n} \sum_{k=0}^{n-1} T^{k} z_{n}-u\right\| \\
& \leq \frac{1}{n} \sum_{k=0}^{n-1}\left\|T^{k} z_{n}-u\right\| \leq \frac{1}{n} \sum_{k=0}^{n-1}\left\|z_{n}-u\right\|=\left\|z_{n}-u\right\| .
\end{aligned}
$$

Thus

$$
\begin{aligned}
\left\|y_{n}-u\right\|^{2} & =\left\|\gamma_{n}\left(x_{n}-u\right)+\left(1-\gamma_{n}\right)\left(w_{n}-u\right)\right\|^{2} \\
& \leq \gamma_{n}\left\|x_{n}-u\right\|^{2}+\left(1-\gamma_{n}\right)\left\|w_{n}-u\right\|^{2} \\
& \leq \gamma_{n}\left\|x_{n}-u\right\|^{2}+\left(1-\gamma_{n}\right)\left\|z_{n}-u\right\|^{2} \\
& =\gamma_{n}\left\|x_{n}-u\right\|^{2}+\left(1-\gamma_{n}\right)\left(\left\|z_{n}-u\right\|^{2}-\left\|x_{n}-u\right\|^{2}\right) \\
& =\gamma_{n}\left\|x_{n}-u\right\|^{2}+\left(1-\gamma_{n}\right)\left(\left\|z_{n}\right\|^{2}-\left\|x_{n}\right\|^{2}+2\left\langle x_{n}-z_{n}, u\right\rangle\right),
\end{aligned}
$$

so $u \in C_{n}$ for all $n \in \mathbb{N}$.

Now by using induction we will show that $F(T) \subset C_{n} \cap Q_{n}$. For $n=1$, we have $x_{1}=x \in C$ and $Q_{1}=C$, since $F(T) \subset Q_{1}$ and hence $F(T) \subset C_{1} \cap Q_{1}$. Assume that $F(T) \subset C_{n} \cap Q_{n}$ for some $n$. Since $x_{n+1}=P_{C_{n} \cap Q_{n}} x$, It follows 
from (2.5) that

$$
\left\langle x_{n+1}-u, x-x_{n+1}\right\rangle \geqslant 0,
$$

for all $u \in C_{n} \cap Q_{n}$. By the induction assumption, we have $F(T) \subset C_{n} \cap Q_{n}$, so we can conclude that for all $u \in F(T)$ the inequality (4.5) holds. On the other hand, by the definition of $Q_{n+1}$, we obtain $F(T) \subset Q_{n+1}$. Therefore, $F(T) \subset C_{n+1} \cap Q_{n+1}$. So $\left\{x_{n}\right\}$ is well-defined. Notice that the definition of $Q_{n}$ implies $x_{n}=P_{Q_{n}} x$. Moreover, $F(T) \subset Q_{n}$, by using (2.3), we have

$$
\left\|x-x_{n}\right\| \leq\|x-u\|, \quad \text { for all } u \in F(T) .
$$

This implies that $\left\{x_{n}\right\}$ is bounded. Since $x_{n+1}=P_{C_{n} \cap Q_{n}} x \in Q_{n}$, we have $x_{n+1} \in Q_{n}$, i.e. $\left\langle x_{n+1}-x_{n}, x_{n}-x\right\rangle \geq 0$. So, by using $(2.3)$, we obtain

$$
\begin{aligned}
\left\|x_{n+1}-x_{n}\right\|^{2} & =\left\|\left(x_{n+1}-x\right)-\left(x_{n}-x\right)\right\|^{2} \\
& =\left\|x_{n+1}-x\right\|^{2}-\left\|x_{n}-x\right\|^{2}-2\left\langle x_{n+1}-x_{n}, x_{n}-x\right\rangle \\
& \leq\left\|x_{n+1}-x\right\|^{2}-\left\|x_{n}-x\right\|^{2} .
\end{aligned}
$$

This yields that

$$
\left\|x_{n+1}-x_{n}\right\| \rightarrow 0
$$

From $x_{n+1} \in C_{n}$, we get

(4.7) $\left\|y_{n}-x_{n+1}\right\|^{2} \leq\left\|x_{n}-x_{n+1}\right\|^{2}+\left(1-\gamma_{n}\right)\left(\left\|z_{n}\right\|^{2}-\left\|x_{n}\right\|^{2}+2\left\langle x_{n}-z_{n}, x_{n+1}\right\rangle\right)$.

Since $\lambda_{n} \rightarrow 1$ and $\left\{x_{n}\right\}$ is bounded, we have

$$
\left\|z_{n}-x_{n}\right\|=\left(1-\lambda_{n}\right)\left\|x_{n}-T x_{n}\right\| \rightarrow 0,
$$

so

(4.9) $\left\|z_{n}\right\|^{2}-\left\|x_{n}\right\|^{2}+2\left\langle x_{n}-z_{n}, x_{n+1}\right\rangle=\left\|z_{n}-x_{n}\right\|^{2}+2\left\langle x_{n}-z_{n}, x_{n+1}-x_{n}\right\rangle \rightarrow 0$.

It follows from (4.6)-(4.9) that $\left\|y_{n}-x_{n+1}\right\| \rightarrow 0$. From (4.6), we obtain

$$
\left\|y_{n}-x_{n}\right\| \leq\left\|y_{n}-x_{n+1}\right\|+\left\|x_{n+1}-x_{n}\right\| \rightarrow 0 \text {. }
$$

Also from $\left\|x_{n}-y_{n}\right\|=\left\|x_{n}-\gamma_{n} x_{n}-\left(1-\gamma_{n}\right) w_{n}\right\|=\left(1-\gamma_{n}\right)\left\|x_{n}-w_{n}\right\|$ and $0 \leq \gamma_{n} \leq \delta<1$, we have $\left\|w_{n}-x_{n}\right\| \rightarrow 0$. It follows from boundedness of $\left\{x_{n}\right\}$ that there exists a subsequence $\left\{x_{n_{i}}\right\}$ of $\left\{x_{n}\right\}$ such that $x_{n_{i}} \rightarrow v$. From $\left\|w_{n}-x_{n}\right\| \rightarrow 0$, we obtain $w_{n_{i}} \rightarrow v$. Since $T$ is a $m$-generalized hybrid mapping, we get

$$
\begin{aligned}
0 \leq & \sum_{j=1}^{m} \beta_{j}\left\|T^{k+m+1-j} x_{n}-y\right\|^{2}+\left(1-\sum_{j=1}^{m} \beta_{j}\right)\left\|T^{k} x_{n}-y\right\|^{2} \\
& -\sum_{j=1}^{m} \alpha_{j}\left\|T^{k+m+1-j} x_{n}-T y\right\|^{2}-\left(1-\sum_{j=1}^{m} \alpha_{j}\right)\left\|T^{k} x_{n}-T y\right\|^{2}
\end{aligned}
$$




$$
\begin{aligned}
= & \sum_{j=1}^{m} \beta_{j}\left(\left\|T^{k+m+1-j} x_{n}-T y\right\|^{2}\right. \\
& \left.+2\left\langle T^{k+m+1-j} x_{n}-T y, T y-y\right\rangle+\|T y-y\|^{2}\right) \\
& +\left(1-\sum_{j=1}^{m} \beta_{j}\right)\left(\left\|T^{k} x_{n}-T y\right\|^{2}\right. \\
& \left.+2\left\langle T^{k} x_{n}-T y, T y-y\right\rangle+\|T y-y\|^{2}\right) \\
& -\sum_{j=1}^{m} \alpha_{j}\left\|T^{k+m+1-j} x_{n}-T y\right\|^{2}-\left(1-\sum_{k=1}^{m} \alpha_{j}\right)\left\|T^{k} x_{n}-T y\right\|^{2} \\
= & \|T y-y\|^{2}+2\left\langle\sum_{j=1}^{m} \beta_{j} T^{k+m+1-j} x_{n}+\left(1-\sum_{j=1}^{m} \beta_{j}\right) T^{k} x_{n}-T y, T y-y\right\rangle \\
& +\sum_{j=1}^{m}\left(\beta_{j}-\alpha_{j}\right)\left(\left\|T^{k+m+1-j} x_{n}-T y\right\|^{2}-\left\|T^{k} x_{n}-T y\right\|^{2}\right),
\end{aligned}
$$

for all $y \in C$ and $k \in \mathbb{N} \cup\{0\}$. Therefore, we obtain

$$
\begin{aligned}
0 \leq & \|T y-y\|^{2}+2\left\langle T^{k} x_{n}-T y, T y-y\right\rangle \\
& +2\left\langle\sum_{j=1}^{m} \beta_{j}\left(T^{k+m+1-j} x_{n}-T^{k} x_{n}\right), T y-y\right\rangle \\
& +\sum_{j=1}^{m}\left(\beta_{j}-\alpha_{j}\right)\left(\left\|T^{k+m+1-j} x_{n}-T y\right\|^{2}-\left\|T^{k} x_{n}-T y\right\|^{2}\right),
\end{aligned}
$$

for all $y \in C$ and $k \in \mathbb{N} \cup\{0\}$. Summing these inequalities from $k=0$ to $n-1$ and dividing by $n$, we get

$$
\begin{aligned}
0 \leq & \|T y-y\|^{2}+2\left\langle w_{n}-T y, T y-y\right\rangle \\
& +2\left\langle\frac{1}{n} \sum_{k=0}^{n-1} \sum_{j=1}^{m} \beta_{j}\left(T^{k+m+1-j} x_{n}-T^{k} x_{n}\right), T y-y\right\rangle \\
& +\frac{1}{n} \sum_{k=0}^{n-1} \sum_{j=1}^{m}\left(\beta_{j}-\alpha_{j}\right)\left(\left\|T^{k+m+1-j} x_{n}-T y\right\|^{2}-\left\|T^{k} x_{n}-T y\right\|^{2}\right) .
\end{aligned}
$$

Substituting $n$ by $n_{i}$ in last inequality, we obtain

$$
\begin{aligned}
0 \leq & \|T y-y\|^{2}+2\left\langle w_{n_{i}}-T y, T y-y\right\rangle \\
& +2\left\langle\frac{1}{n_{i}} \sum_{k=0}^{n_{i}-1} \sum_{j=1}^{m} \beta_{j}\left(T^{k+m+1-j} x_{n_{i}}-T^{k} x_{n_{i}}\right), T y-y\right\rangle \\
& +\frac{1}{n_{i}} \sum_{k=0}^{n_{i}-1} \sum_{j=1}^{m}\left(\beta_{j}-\alpha_{j}\right)\left(\left\|T^{k+m+1-j} x_{n_{i}}-T y\right\|^{2}-\left\|T^{k} x_{n_{i}}-T y\right\|^{2}\right) .
\end{aligned}
$$


By taking the limit as $i \rightarrow \infty$, we obtain

$$
0 \leq\|T y-y\|^{2}+2\langle v-T y, T y-y\rangle,
$$

since $w_{n_{i}} \rightarrow v$. By putting $y=v$ in (4.10), we get $0 \leq-\|T v-v\|^{2}$ and thus $T v=v$. Let $u_{0}=P_{F(T)} x$. Since $u_{0}=P_{F(T)} x \in C_{n} \cap Q_{n}$ and $x_{n+1}=P_{C_{n} \cap Q_{n}} x$, we have

$$
\left\|x-x_{n+1}\right\|^{2} \leq\left\|x-u_{0}\right\|^{2} .
$$

Since $x_{n_{i}} \rightarrow v$ and $\|\cdot\|^{2}$ is weakly lower semicontinuous, we get

$$
\begin{aligned}
\|x-v\|^{2} & =\|x\|^{2}-2\langle x, v\rangle+\|v\|^{2} \leq \liminf _{i \rightarrow \infty}\left(\|x\|^{2}-2\left\langle x, x_{n_{i}}\right\rangle+\left\|x_{n_{i}}\right\|^{2}\right) \\
& =\liminf _{i \rightarrow \infty}\left\|x-x_{n_{i}}\right\|^{2} \leq\left\|x-u_{0}\right\|^{2} .
\end{aligned}
$$

Now, the definition of $u_{0}$, implies that $v=u_{0}$. Thus we obtain that $x_{n} \rightarrow u_{0}$.

Finally, we prove that $x_{n} \rightarrow u_{0}$. It follows from (2.3) that

$$
\left\|u_{0}-x_{n}\right\|^{2}=\left\|u_{0}-x\right\|^{2}+\left\|x-x_{n}\right\|^{2}+2\left\langle u_{0}-x, x-x_{n}\right\rangle,
$$

for all $n \in \mathbb{N}$. So, by using (4.11), we get

$$
\begin{aligned}
\limsup _{n \rightarrow \infty} & \left\|u_{0}-x_{n}\right\|^{2}=\limsup _{n \rightarrow \infty}\left(\left\|u_{0}-x\right\|^{2}+\left\|x-x_{n}\right\|^{2}+2\left\langle u_{0}-x, x-x_{n}\right\rangle\right) \\
& \leq \limsup _{n \rightarrow \infty}\left(\left\|u_{0}-x\right\|^{2}+\left\|x-u_{0}\right\|^{2}+2\left\langle u_{0}-x, x-x_{n}\right\rangle\right) \\
& =\left(\left\|u_{0}-x\right\|^{2}+\left\|x-u_{0}\right\|^{2}+2\left\langle u_{0}-x, x-u_{0}\right\rangle\right)=\left\|u_{0}-u_{0}\right\|^{2}=0 .
\end{aligned}
$$

This yields that $\lim _{n \rightarrow \infty}\left\|u_{0}-x_{n}\right\|=0$. Thus $\left\{x_{n}\right\}$ converges strongly to $u_{0}$.

\section{REFERENCES}

[1] R.P. Agarwal, D. O'Regan and D.R. Sahu, Fixed Point Theory for Lipschitzian-type Mappings with Applications, Springer, 2009.

[2] K. Aoyama, Y. Kimura, W. Takahashi and M. Toyoda, Approximation of common fixed points of a countable family of nonexpansive mappings a Banach space, Nonlinear Anal. 67 (2007), 2350-2360.

[3] C.E. Chidume and S.A. Mutangadura, An example on the Mann iteration method for Lipschitz pseudocontractions, Proc. Amer. Math. Soc. 129 (2001), 2359-2363.

[4] A. Genel and J. Lindenstrass, An example concerning fixed points, Israel J. Math. 22 (1975), 81-86.

[5] B. Halpern, Fixed points of nonexpanding maps, Bull. Amer. Math. Soc. 73 (1967), 957-961.

[6] M. Hojo, W. Takahashi and I. Termwuttipong, Strong convergence theorem for 2generalized hybrid mappings in Hilbert spaces, Nonlinear Anal. 75 (2012), 2166-2176.

[7] S. Iемото And W. TAKAhashi, Approximating fixed points of nonexpansive mappings and nonspreading mappings in a Hilbert space, Nonlinear Anal. 71 (2009), 2080-2089.

[8] S. Ishikawa, Fixed points by a new iteration method, Proc. Amer. Math. Soc. 40 (1974), $147-150$.

[9] S. Iтон AND W. TAKAhashi, The common fixed point theory of single-valued mappings and multi-valued mappings, Pacific J. Math. 79 (1978), 493-508. 
[10] T.H. Kim AND H.K. Xu, Strong convergence of modified Mann iterations, Nonlinear Anal. 61 (2005), 51-60.

[11] T.H. Kim AND H.K. Xu, Strong convergence of modified Mann iterations for asymptotically nonexpansive mappings and semigroups, Nonlinear Anal. 64 (2006), 1140-1152.

[12] P. KocoureK, W. TAKAhashi AND J.-C. YAO, Fixed point theorems and weak convergence theorems for generalized hybrid mappings in Hilbert spaces, Taiwanese J. Math. 6 (2010), $2497-2511$.

[13] F. KOHSAKA AND W. TAKAHASHI, Fixed point theorems for a class of nonlinear mappings related to maximal monotone operators in Bnach spaces, Arch. Math., 91 (2008), 166-177.

[14] Y. Kurokawa and W. Takahashi, Weak and convergence theorems for nonspreading mappings in Hilbert spaces, Nonlinear. Anal. 73 (2010) 1562-1568.

[15] W.R. Mann, Mean value methods in iteration, Proc. Amer. Math. Soc. 4 (1953), 506-510.

[16] G. MARINo AND H.K. XU, Weak and strong convergence theorems for strict pseudocontractions in Hilbert spaces, J. Math. Anal. Appl. 329 (2007), 336-346.

[17] C. Martinez-Yanes and H.K. Xu, Strong convergence of CQ method fixed point biteration processes, Nonlinear Anal. 64 (2006), 2400-2411.

[18] T. Maruyama, W. Takahashi and M. Yao, Fixed point and mean ergodic theorems for new nonlinear mappings in Hilbert spaces, J. Nonlinear Convex Anal. 12 (2011), 185-197.

[19] K. Nakajo And W. Takahashi, Strong convergence theorems for nonexpansive mappings and nonexpansive semigroups, J. Math. Anal. Appl. 279 (2003), 372-379.

[20] M.O. Osilike And F.O. Isiogugu, Weak and strong convergence theorems for nonspreading-type mappings in Hilbert spaces, Nonlinear. Anal. 74 (2011), 1814-1822.

[21] W. TAkahashi, Introduction to Nonlinear and Convex Analysis, Yokohoma Publishers, Yokohoma, 2009.

[22] _ Fixed point theorems for a new nonlinear mappings in a Hilbert space, J. Nonlinear Convex Anal. 11 (2010), 79-88.

[23] W. TAKAHASHI AND M. TOYODA, Weak convergence theorems for nonexpansive mappings and monotone mappings, J. Optim. Theory Appl. 118 (2003), 417-428.

[24] W. TAkahashi And J.-C. YaO, Fixed point theorems and ergodic theorems for nonlinear mappings in Hilbert spaces, Taiwanese J. Math. 15 (2011), 457-472.

[25] W. Takahashi, J.-C. Yao and M.-H. Hsu, Generalized hybrid mappings in Hilbert spaces and Banach spaces, Taiwanese. J. Math. 16 (2012), 129-149.

[26] W. TAKahashi, J.-C. YaO And F. Kohsaka, The fixed point property and unbounded sets in Banach spaces, Taiwanese J. Math. 14 (2010), 733-742.

[27] F. YAn, Y. Su AND Q. Feng, Convergence of Ishikawa method for generalized hybrid mappings, Commun. Korean Math. Soc. 28 (2013), No. 1, 135-141.

[28] H. ZHOU, Convergence theorems of fixed points for Lipschits pseudo-contractions, J. Math. Anal. Appl. 243 (2008), 546-556.

Manuscript received October 8, 2013

Sattar Alizadeh and Fridoun Moradlou

Department of Mathematics

Sahand University of Technology

Tabriz, IRAN

E-mail address: sa_alizadeh@sut.ac.ir,moradlou@sut.ac.ir, fridoun.moradlou@gmail.com

TMNA : Volume $46-2015-\mathrm{N}^{\mathrm{O}} 1$ 